\title{
The Content of Pronouns: Evidence from Focus
}

\author{
Uli Sauerland \\ Tübingen University
}

This paper is part of an effort to learn something about the semantics of pronominals from their focus properties. At present, I believe to have evidence substantiating the following two claims: Claim 1 is that Bound Pronominals can be hidden definite descriptions, but probably need not necessarily be. Claim 2 is that donkey anaphora must be hidden definite descriptions.

The evidence for Claim 1 comes from a new analysis of cases with focus on bound pronouns such as (1) that also featured in earlier work of mine (Sauerland 1998, 1999).

(1) On Monday, every boy called his mother.

On TUESday, every TEAcher called his/HIS mother.

In particular, I show parallels of focus on bound pronouns and bound definite descriptions (epithets).

The evidence for Claim 2 comes from cases like (2) where focus seems to be obligatory.

(2) a. Every girl who came by car parked it in the lot.

b. Every girl who came by bike parked \#it/IT in the lot.

\section{Bound Pronouns can Differ in Meaning}

\subsection{Necessary Condition for the Licensing of Focus}

The results of this paper are compatible with Schwarzschild's (1999) theory of focus. For convenience, however, I use the licensing condition in (3). This is only a necessary condition, not a sufficient condition for focus licensing. Schwarzschild's (1999) theory entails that condition (3) is necessarily fulfilled for a focussed XP unless there's no YP dominating XP or the YP immediately dominating XP is also focussed. ${ }^{1}$

(3) A focus on XP is licensed only if there are a Focus Domain constituent FD dominating XP and a Focus Antecedent constituent FA in the preceding 
discourse (or entailed from it) that satisfy:

a. $\llbracket F A \rrbracket \in \llbracket F D \rrbracket_{f}$. (I.e., there's a Focus-Alternative FD' of FD with $\left.\llbracket F A \rrbracket=\llbracket F D^{\prime} \rrbracket\right)$

b. Contrastiveness: $\llbracket \mathrm{FA} \rrbracket \notin \llbracket \mathrm{FD}^{-} \rrbracket_{f}$, where $\mathrm{FD}^{-}$is identical to $\mathrm{FD}$, except that XP isn't focussed in $\mathrm{FD}^{-}$.

\subsection{An Illustration}

Consider example (4) for a simple demonstration of how (3) is applied. In (4), the discourse doesn't license the focus on Mary in (4a), but licenses all foci in (4b) and $(4 c)$.

(4) Discourse: On Monday, Bob called Mary.

a. \#On TUESday, JIM called MARY.

b. On TUESday, JIM called Mary.

c. On TUESday, JIM called SUE.

The focus on Mary in (4a) isn't licensed, because Contrastiveness is violated. Consider the choices of FA and FD in (5). Condition (3a) is satisfied for FA and FD with the focus alternative $\mathrm{FD}^{\prime}$ in (5c). However, also $\mathrm{FD}^{-}$where the focus on Mary is absent has a focus alternative that means the same as FA, as shown in (5e), violating Contrastiveness.
a. $\mathrm{FA}=$ Bob called Mary
b. $\mathrm{FD}=[\mathrm{JIM}]_{F}$ called $[\mathrm{MARY}]_{F}$
c. $\mathrm{FD}^{\prime}=$ Bob called Mary
d. $\mathrm{FD}^{-}=[\mathrm{Jim}]_{F}$ called Mary
e. $\mathrm{FD}^{-\prime}=$ Bob called Mary $\Longrightarrow \llbracket \mathrm{FA} \rrbracket=\llbracket \mathrm{FD}^{-\prime} \rrbracket \# \#$

\subsection{Application to Bound Pronouns}

What does the application of Contrastiveness tell us about bound pronouns? In this section, I show under certain circumstances two occurences of bound pronouns must differ in meaning as proposed in Sauerland $(1998,1999)$. In particular, this is the case when there's a focussed bound pronoun and an antecedent with a bound pronoun in a parallel position.

Look at (6) with focus on the bound pronoun his in (6b). Intuitively, the focus seems to involve a contrast between his in the discourse and the focussed his and for this the two occurences of his must somehow differ in interpretation. Indeed, this is the inescable conclusion of the semantics of focus I adopt.

Discourse: On Monday, every boy called his mother.

a. On TUESday, every TEAcher called HIS mother.

To show this, all possible choices of FA and FD must be looked at to verify that focus on HIS is only licensed if HIS and his differ in interpretation. I'll actually only consider two examplary cases of FA and FD. First, I look at FA and FD in (7) that 
don't include the binders, then in (8) at FA and FD that include the binders of the two pronouns.
a. $\mathrm{FA}=$ his mother
b. $\mathrm{FD}=[\mathrm{HIS}]_{F}$ mother
c. $\mathrm{FD}^{\prime}=$ Mary's mother
d. $\mathrm{FD}^{-}=$his mother

For the FA and FD in (7), Contrastiveness requires that $\llbracket \mathrm{FA} \rrbracket \notin \llbracket \mathrm{FD}^{-} \rrbracket_{f}$ and this

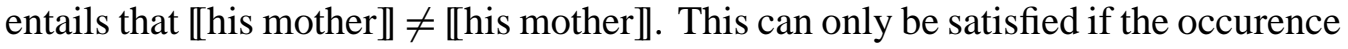
of his in FA and that in $\mathrm{FD}^{-}$have different interpretations.

Now, consider FA and FD in (8), which include the binder.
a. $\mathrm{FA}=$ Every boy called his mother.
b. $\mathrm{FD}=$ Every $[\text { TEAcher }]_{F}$ called $[\mathrm{HIS}]_{F}$ mother
c. $\mathrm{FD}^{\prime}=$ Every boy called his mother
d. $\mathrm{FD}^{-}=$Every $[\text {teacher }]_{F}$ called his mother

Contrastiveness requires that the focus alternative $\mathrm{FD}^{-\prime}$ of $\mathrm{FD}^{-}$shown in (9) differ in interpretation from FA. Again the occurences of his in (9) must somehow have different interpretations for (9) to be true.

(9) $\quad \llbracket \mathrm{FD}^{-\prime} \rrbracket=\llbracket$ Every boy called his mother $\rrbracket \neq \llbracket$ Every boy called his mother $\rrbracket$ $=\llbracket \mathrm{FA} \rrbracket$

For these reasons, I see no real alternative to the conclusion that bound pronouns are ambiguous in a way not evident from their segmental phonology. One apparent alternative would be to say that focus on the pronoun can be inherited by some form of agreement with the antecedent. This intuition here is drawn from the observation that at least parts of the antecedent of the pronoun in (6a) are focussed. However, there are numerous problems for this idea. (10) is a case where the the idea predicts too many antecedents to be possible for the focussed pronoun: Both QPs, every boy and every teacher in (10) are equal in their focus structure. Nevertheless only the latter QP can be the antecedent of the focussed pronoun HIS in (10).

(10) *Every BOY called his mother before every TEAcher called HIS mother.

\section{Old Account: Indices Explain Everything}

This section summarizes and ultimately rejects earlier work of myself on focussed bound pronouns. Sauerland $(1998,1999)$ adopts the standard assumption that bound pronouns are indexed variables, and claims that differences in indexation alone explain their focussability. Consider the representation of (6) with indices given in (11).

(11) Discourse: On Monday, every boy $\lambda_{1} t_{1}$ called his ${ }_{1}$ mother 
a. On TUESday, every TEAcher $\lambda_{2} t_{2}$ called $\mathrm{HIS}_{2}$ mother

For the choices of focus domain and antecedent in (12), the contrastiveness condition is arguably satisfied. The requirement imposed by Contrastiveness for (12) is that $\llbracket \mathrm{FA} \rrbracket \neq \llbracket \mathrm{FD}^{-} \rrbracket$.
a. $\mathrm{FA}=\mathrm{his}_{1}$ mother
b. $\mathrm{FD}=\left[\mathrm{HIS}_{2}\right]_{F}$ mother
c. $\mathrm{FD}^{\prime}=$ his $_{1}$ mother
d. $\mathrm{FD}^{-}=$his $_{2}$ mother $\Longrightarrow \exists \mathrm{g}: \llbracket \mathrm{FA} \rrbracket^{g} \neq \llbracket \mathrm{FD}^{-} \rrbracket^{g}$

Contrastiveness as stated in (3b) above cannot be applied to (12) since FA and FD ${ }^{-}$ both contain an unbound variable. A restatement of contrastiveness could in fact be done in either a way to make the resulting condition sensitive to differences in indexation as in (13) or to make it not sensitive to such differences. Since the focus in (6) is licensed, for the account of Sauerland (1998, 1999), the statement (13a) must be adopted. Then contrastiveness is satisfied in (12) because, for any $g$ with different results for 1 and 2 , $\llbracket \mathrm{FA} \rrbracket^{g} \neq \llbracket \mathrm{FDs} \rrbracket^{g}$

(13) a. Contrastiveness (index-sensitive): for all Focus Alternatives $\mathrm{FD}^{-\prime}$ of $\mathrm{FD}^{-}$there is an assignment $g$ such that $\llbracket \mathrm{FA} \rrbracket^{g} \neq \llbracket \mathrm{FDs}^{\prime} \rrbracket^{g}$

b. Contrastiveness (index-insensitive): for all Focus Alternatives $\mathrm{FD}^{-\prime}$ of $\mathrm{FD}^{-}$and for every assignment $g: \llbracket \mathrm{FA} \rrbracket^{g} \neq \llbracket \mathrm{FDs}^{\prime} \rrbracket^{g}$

\subsection{One Problem: Adnominal "however" and "too"}

By now, I know of a number of problems for the account of Sauerland (1998, 1999) and discuss some of relevant data in the next section. The problem shown in this section is related to a basic property of indexed variables - the fact that two representations that are identical except for the index of a variable binder and all variables bound by it don't differ in interpretation. In this situation, the two representations are called alphabetic variants of one another. This can be illustrated for (11) by considering the FA and FD in (14), which include the binders of the two pronouns. For (14), the focus licensing conditions are not satisfied (cf. Rooth 1992b), because FA and $\mathrm{FD}^{-}$are alphabetic variants, and therefore don't differ in interpretation.
a. $\mathrm{FA}=\lambda_{1} t_{1}$ called his mother $_{1}$
b. $\mathrm{FD}=\lambda_{2} t_{2}$ called $\left[\mathrm{HIS}_{2}\right]_{F}$ mother
c. $\mathrm{FD}^{\prime}=\lambda_{2} t_{2}$ called his ${ }_{2}$ mother
d. $\mathrm{FD}^{-}=\lambda_{2} t_{2}$ called his 2 mother $\Longrightarrow \llbracket \mathrm{FA} \rrbracket=\llbracket \mathrm{FD}^{-} \rrbracket \# \#$

The equivalence of alphabetic variants predicts therefore that two occurences of bound variables shouldn't be able to contrast when the compared constituents include their binders. This prediction can be tested if there are means to control for size of the compared constituents. I think that the focus sensitive particles however and 
too (as well as many similar expressions) provide these means, in particular the adnominal variants of these.

As far as I know, no descriptive work on however has been done, but it's essential properties can be captured quite easily. Consider the paradigm in (15): Adnominal however construed with the subject presupposes that both the subject and the VP differ in meaning with an antecedent. ${ }^{2,3}$
Discourse: Carl called Mary.
a. JOHN however WROte Mary.
b. JOHN however called BERTA
c. \#JOHN however called Mary.
d. \#Carl however called BERta.

The contrasts of accetability in (15) can be captured as a presupposition of however. For example, (15b) seems to have the presuppositions, that there are $X$ and $Y$ such that a) $X$ called $Y$, b) $X$ didn't call Berta, and c) John didn't call $Y$. Given the discourse in (15) the presupposition is fulfilled with $X=$ Carl and $Y=$ Mary. Generalizing this picture a little, I propose that the presupposition for adnominal however is the following:

(16) $\llbracket[\mathrm{NP}$ however $] \mathrm{VP} \rrbracket$ presupposes that there are focus alternatives $\mathrm{NP}^{\prime}$ and $\mathrm{VP}^{\prime}$ of NP and VP respectively such that:
a. $\llbracket \mathrm{NP}^{\prime} \mathrm{VP}^{\prime} \rrbracket=1$,
b. $\llbracket \mathrm{NP}^{\prime} \mathrm{VP} \|=0$, and
c. $\llbracket \mathrm{NP} V \mathrm{VP}^{\prime} \rrbracket=0$.

The argument in the following is now based on the observation that (17a) is acceptable, where however is attached to the antecedent of the bound pronoun and the bound pronoun intuitively is contrasted with another occurrence of a bound pronoun in the discourse. As the unacceptability of (17b) without focus on the bound pronoun shows, the focus on the bound pronoun satisfies the presupposition of however.

(17) Discourse: Every teacher believes that she'll win.

a. Every GIRL, however, believes that SHE'll win.

b. \#Every GIRL, however, believes that she'll win.

It turns out that the fact in (17) isn't predicted on the index based account of focus on bound pronouns. The indexed representation of (17a) is (18a). The focus alternatives licensing however should be the $\mathrm{NP}^{\prime}$ in (18b) and for the VP I consider the two possibilities in (18c) and (18d) - it's not clear whether VP" should be available as a focus alternative, but I consider it here just for the arguments sake.

(18) a. [NP every GIRL] however [ ${ }_{V P} \lambda_{2} t_{2}$ believes that $\mathrm{SHE}_{2}^{\prime}$ 'll win.]

b. $\mathrm{NP}^{\prime}=$ every teacher

c. $\mathrm{VP}^{\prime}=\lambda_{2} t_{2}$ believes that she ${ }_{1}^{\prime} l l$ win.

d. $\mathrm{VP}^{\prime \prime}=\lambda_{1} t_{1}$ believes that she ${ }_{l}^{\prime}$ ll win. 
For $\mathrm{NP}^{\prime}$ and $\mathrm{VP}^{\prime}$ none of the focus licensing conditions are satisfied, in the discourse in (16): Since $s h e_{1}$ is an unbound variable, in (18c) the satisfaction of the three licensing conditions is not affected by the presence of the discourse antecedent in (17), but rather depends on what the assignment assigns to index 1 . This is clearly not the desired result. The focus licensing conditions are also not satisfied for $\mathrm{VP}^{\prime \prime}$ in (18d): Since $\mathrm{VP}^{\prime \prime}$ and VP are alphabetic variants, the presuppositions (16b) and (16c) of however aren't satisfied for $\mathrm{NP}^{\prime}$ and $\mathrm{VP}^{\prime \prime}$. Therefore, the incorrect prediction made by the index based account is that (17a) should be just as unacceptable as (17b).

An argument similar to the one with however can be made with adnominal too. There's some descriptive work on too and words with similar meaning in general, but I don't know of any work addressing specifically the adnominal use of too illustrated in (19). Adnominal too seems to presuppose that for a focus alternative to the subject, the VP is true.

Discourse: Carl visited Mary.

a. JOHN too visited Mary.

b. ${ }^{*} \mathrm{JOHN}$ too visited BERta.

Applying Soames's (1989) insights on the semantics of too to the adnominal case, I propose the semantics in (20).

(20) $\llbracket \mathrm{NP}$ too $\mathrm{VP} \rrbracket$ presupposes that there is a focus alternative $\mathrm{NP}^{\prime}$ of NP such that

a. $\llbracket \mathrm{NP}^{\prime} \mathrm{VP} \rrbracket=1$.

Consider now the example in (21), which combines adnominal too with variable binding. As (21b) shows, the presence of too doesn't allow the bound variable to be focussed.

(21) Discourse: Every teacher believes that she'll win.

a. Every GIRL, too, believes that she'll win.

b. \#Every GIRL, too, believes that SHE'll win.

The oddness of (21b) is not predicted by the index based account of focus in such examples. Specifically, the indexed representation in (22), shows that the VP here is predicted to be true of the $\mathrm{NP}^{\prime}$ every teacher, and therefore the presupposition of too should be fulfilled in (21b).

\section{[NP every GIRL] too [VP $\lambda_{2} t_{2}$ believes that $\mathrm{SHE}_{2}$ 'll win]}

To sum up this section, consider where it advanced the description of the phenomon over that of the previous section. In the previous section, I showed that two occurences of a bound pronoun can differ in meaning. In this section, I showed that the difference in meaning between two bound pronouns can be such that even otherwise identical constituents in which the bound variables are bound differ in interpretation. This is not predicted by the assumption that differences in indexation alone license focus. ${ }^{4}$ 


\section{New Account: Pronouns as Definites}

My new proposal is that bound pronouns can optionally be hidden definite descriptions. Put, in other words I claim that E-type pronouns can be bound. This proposal is illustrated in (23). I claim that that (23a) has one structure identical to (23b) with an overt epithet.

(23) a. One relative of every boy ${ }_{i}$ expected that he ${ }_{i}$ would win.

b. One relative of every boy $_{i}$ expected that the ${ }_{i}$ boy would win.

For the interpretation of bound E-type pronouns, I assume the same semantic rule that is independently required for epithets, which is given in (24).

(24) $\llbracket(t) h e_{i} \mathrm{P} \rrbracket^{g}$ presupposes that $P(g(i))=1$.

When defined: $\llbracket(t) h e_{i} \mathrm{P} \rrbracket^{g}=g(i)$

An important question for the account is: What precisely is the content of the definite description a pronoun corresponds to? I start with the assumption that, if a pronoun with antecedent [D NP] is analyzed as a hidden definite description, then the pronoun must be the definite description [the NP]. This seems to be the simplest assumption at this point, though it might well need revision in the end. ${ }^{5}$

\subsection{Account of Focus Licensing}

How does the assumption that bound pronouns can be definite descriptions explain the possibility of focus on a bound pronoun? Consider again (25) (repeated from (6)) with focus on the bound pronoun.

(25) Discourse: On Monday, every boy called his mother.

a. On TUESday, every TEAcher called HIS mother.

The new account allows the representations in (26) where both bound pronounsthat in the discourse antecedent and that in target sentence-are bound definite descriptions.

(26) Discourse: every boy $\lambda_{1} t_{1}$ called the $e_{1}$ boy's mother

a. every TEAcher $\lambda_{2} t_{2}$ called [the ${ }_{2}$ teacher's $]_{F}$ mother

One seletion of FA and FD from (26) that satisfies the focus licensing conditions is given in (27).
a. $\mathrm{FA}=\lambda_{1} t_{1}$ called the ${ }_{1}$ boy's mother
b. $\mathrm{FD}=\lambda_{2} t_{2}$ called [the ${ }_{2}$ teacher's $]_{F}$ mother
c. $\mathrm{FD}^{\prime}=\lambda_{2} t_{2}$ called [the ${ }_{2}$ boy's $]_{F}$ mother
d. $\mathrm{FD}^{-}=\lambda_{2} t_{2}$ called the ${ }_{2}$ teacher's mother

In particular, contrastiveness is satisfied because $\mathrm{FA}$ and $\mathrm{FD}^{-}$denote functions with different domains: 

a. $\llbracket[\mathrm{FA} \rrbracket=f$ where $f:\{x$ : teacher $(x)=1\} \mapsto\{0,1\}, \ldots$
b. $\llbracket \mathrm{FD}^{-} \rrbracket=g$ where $g:\{x: \operatorname{boy}(x)=1\} \mapsto\{0,1\}, \ldots$

Since the FA and FD considered in (27) contain the binders of the bound pronouns, it's been shown here that the new account predicts a difference in meaning between these constituents. This also explains why the use of adnominal however is licit.

\subsection{On Binding Theory}

Postal (1972), Lasnik (1976, 1989), and Dubinsky and Hamilton (1998) discuss syntactic restrictions on the use of epithets. For example, Postal (1972) claims that epithets must not be c-commanded at surface structure by their antecedents, and this captures the contrasts in (29) and (30) correctly.

(29) a. Some friend of $\mathrm{John}_{i}$ 's thinks that I admire the ${ }_{i}$ idiot.

b. ${ }^{*} \mathrm{John}_{i}$ thinks that I admire the $\mathrm{i}_{i}$ idiot.

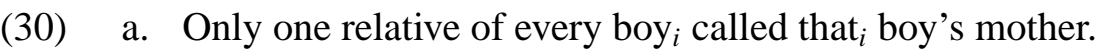

b. *Every boy $_{i}$ called that ${ }_{i}$ boy's mother.

If my proposal is correct, E-type pronouns are not subject to this restriction-for example in (26), the putative E-type pronoun is c-commanded by its antecedent at surface structure. At present I know no good answer to this problem. What I can say is that there are two English definite determiners, he/she/it and the, with different syntactic properties-specifically, only the is subject to Condition C. ${ }^{6}$

\section{Further Support}

\subsection{Antecedent Effect}

One piece of further support for my new claim comes from the following observation: If the antecedent of the bound pronoun in the F-antecedent is identical to the antecedent of the bound pronoun in the F-domain, the latter pronoun cannot be focussed. (Thanks to Irene Heim (p.c.) for first hinting at the data in this section.) This is illustrated in (31) and (32).

(31) Discourse: Did every boy call his mother?

a. \#Yes, every boy called HIS mother.

b. No, every TEAcher called HIS mother.

(32) Discourse: I didn't expect every teacher to get what she wanted.

a. \#But, every teacher GOT what SHE wanted.

b. In the end, every GIRL got what SHE wanted.

This antecedent effect follows from the new proposal. Consider the representations for (31) in (33). 
a. Every boy $\lambda_{1} t_{1}$ called the end $_{1}$ boy's mother

b. Every boy $\lambda_{2} t_{2}$ called the $e_{2}$ boy's mother

For the FA and FD in (34), which are analogous to the domains considered in the analysis of (26) above, contrastiveness is violated, because $\mathrm{FD}^{-}$and $\forall$ are identical in meaning.

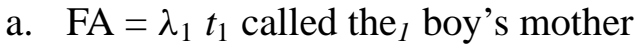
b. $\mathrm{FD}=\lambda_{2} t_{2}$ called [the boy's $_{F}$ mother
c. $\mathrm{FD}^{\prime}=\lambda_{2} t_{2}$ called [the ${ }_{2}$ boy's $]_{F}$ mother
d. $\mathrm{FD}^{-}=\lambda_{2} t_{2}$ called the 2 boy's mother $\Longrightarrow \llbracket \mathrm{FD}^{-} \rrbracket=\llbracket \mathrm{FA} \rrbracket$

The demonstration that the focus licensing condition isn't satisfied for a particular choice of FA and FD is of course not sufficient to explain the impossibility of focus: It needs to be shown that for every permissible choice of FA and FD, the focus licensing condition isn't satisfied. In particular, the question is whether a choice of FA and FD that don't include the binder would incorrectly license the focus in (31) and (32) when different indices are used as in the representations in (33). At this point, I see two ways to block this prediction: Either the index-insensitive focus licensing condition (13b) is adopted, or there's a condition that excludes the FDs that don't exclude the antecedent from consideration-in fact, Schwarzschild's (1999) proposal would do so. If either of these routes is chosen, the antecedent effect follows from the new proposal.

The antecedent effect raises a number of further issues to investigate. I address some of these in the appendix. The discussion there of cases where the domains of the antecedents aren't identical, but overlap also speaks to the question of whether focus isn't incorrectly predicted to be licensed if the bare variable analysis is chosen for the pronoun in the antecedent.

\section{$4.2 \bar{A}$-Traces and Pronouns Mean the Same}

A second prediction of my proposal arises from what is known about traces. It has been argued that traces are syntactically and semantically definite descriptions, with unpronounced parts (Chomsky 1993, Fox 1999, Sauerland 1998).

Therefore, my proposal predicts that $\bar{A}$-traces should be able to license destressing of pronouns as Danny Fox (p.c.) first pointed out to me. More over, an effect like the antecedent effect in the previous section is expected: The destressing of pronoun should be possible if and only if the antecedents are lexically the same. This prediction is bourne out by (35) (after Fox, p.c.) and (36).

a. I saw [every picture of every man who wanted me to see \#him/HIM today $]_{D P_{1}}$.

b. I saw [every picture of every man who wanted me to see it/\#IT today $]_{D P_{1}}$.

a. Every student ${ }_{i}$ beat every teacher ${ }_{j}$ who expected that she $e_{i}$ beat her ${ }_{j}$.

b. Every student ${ }_{i}$ beat every teacher ${ }_{j}$ who expected that $\mathrm{SHE}_{j}$ beat $\mathrm{HER}_{i}$. 
Consider the LF-representation of (36b) in (37). Since the example exhibits antecedent contained destressing, I assume that QR of the object is required. Therefore, FA in (37) contains two traces, the trace of the subject and the QR trace of the object. These traces contrast with the two focussed pronominals in FD.

(37) [every student] $\lambda_{1}$ [every teacher

$\left[\lambda_{2} t_{2}\right.$ expected that $\left[\text { the }_{1} \text { teacher }\right]_{F}$ beat $\left.\left.\left[\text { the }_{2} \text { student }\right]_{F}\right]\right]$

$\lambda_{2} \underbrace{\left[\text { the }_{l} \text { student] beat [the }\right.}{ }_{2}$ teacher]

FD

FA

\subsection{Non-conservative Quantifiers}

Does the E-type representation of bound pronouns ever have an effect on the semantics? Consider again the two alternative representations proposed for bound pronouns in (38) with $Q$ being any quantifier. (38a) and (38b) don't in general have the same interpretation-the scope of $Q$ in (38b) presupposes teacher-hood.

(38) $Q$ teacher called his mother

a. $Q$ teacher $\lambda_{1} t_{1}$ called $x_{l}$ 's mother

b. $Q$ teacher $\lambda_{1} t_{1}$ called the ${ }_{1}$ teacher's mother

For conservative quantifiers $Q$, the presupposition of (38b) is always satisfied (cf. Fox 1999 on $\bar{A}$-traces). With non-conservative quantifiers, however, representation (38b) should result in a presupposition failure.

I claim that the predicted effect can be demonstrated in examples with bound indexicals pronoun. Irene Heim (p.c.) first observed that examples with only show that indexicals in English can be bound. Consider the ambiguity of example (39): The two readings arise depending on whether the second occurence of you is bound by the first, or whether it's coreferent with it, but not bound.

(39) Only you brought something you like.

a. Only you $\lambda_{1} t_{1}$ brought something $x_{1}$ liked (bound) entails: Nobody else brought something he likes.

b. Only you $\lambda_{1} t_{1}$ brought something you like (coreferent) entails: Nobody else brought something you like.

A similar ambiguity is found in (40) with the indexical $I$.

(40) Only I know when I came.

My argument is based on the new observation that (39) and (40) are disambiguated by focus. A focussed indexical cannot be bound, as shown by (41a). A destressed indexical, on the other hand, prefers the bound interpretation.

(41) a. Only YOU brought something YOU like. (coreferent, *bound)

b. Only YOU brought something you like. (bound, ?? coreferent) 
Further evidence is in (42): In (42a), the bound reading is blocked by focus on you.

(42) Discourse: Everybody else likes all his colleagues.

a. Only you have colleagues you/\#YOU can't stand.

Consider the representation in (43) with a bound E-type you, which is required for focus licensing ${ }^{7}-\mathrm{I}$ assume here that you has an interpretation as a predicate true only of the person addressed.

(43) Only you $\lambda_{1} t_{1}$ brought something [the ${ }_{1}$ you] like

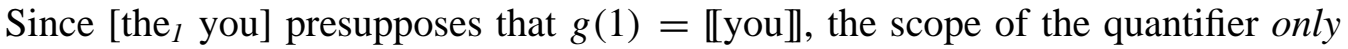
you in (44) is a function with a singleton set as its domain - therefore, (43) is either trivially true or a presupposition failure. Intuitively, the sentence (42a) with focus on you is paraphrasable as the tautologous: Only you are you and brought something you like. Plausibly, this tautologous interpretation isn't considered available when judging (41a) and therefore only the coreferent interpretation is available. ${ }^{8}$

(44) $\llbracket \lambda_{1} t_{1}$ brought something [the ${ }_{l}$ you $]$ like $\rrbracket=f$ with

$f:\{y o u\} \mapsto\{1,0\}$

\section{Donkey Anaphora and Focus}

For bound pronouns, I argued that they can be either bare variables or hidden definite descriptions and that focus forces the definite description analysis. A natural question to ask is what the focus properties of pronouns that aren't bound are. In this section, I present some preliminary results on donkey anaphora: It seems that these must obligatorily bear focus under the conditions where two bound pronouns were optionally focussed. I then show that this result is predicted by the E-type analysis of donkey anaphora according to which they are obligatorily definite descriptions.

Graham Katz (p.c.) first pointed out to me that a donkey anaphor must be focussed when its antecedent differs in examples like (45a). In this example, there is a parallel donkey anaphor in the discourse, which has a different antecedent: $a$ boy is in the discourse, a man in the target sentence. As (45b)shows, an antecedent effect is observed with donkey anaphora as well-the focus on the donkey anaphor is impossible, when the antecedents of the two donkey anaphora are the same.

(45) Discourse: Monday night, every girl who was visiting a boy gave him flowers.

a. TUESday night, every girl who was visiting a MAN gave HIM CHOColate.

b. \#TUESday night, every girl who was visiting a boy gave HIM CHOColate.

The judgement that focus on the donkey anaphor is obligatory in (45a) is confirmed by some further tests. Section 2.1 above showed that adnominal however requires a focus in the VP, while too disallows it. Using this test, confirms in (46) and (47) 
that the donkey anaphor is obligatorily focussed: (46a) with too is odd, since too doesn't allow a contrast in its scope. ${ }^{9}$

(46) Discourse: Every owner of a car parked it in the lot.

a. \#Every owner of a BIKE too parked it in the lot.

b. Every owner of a BIKE however parked IT in the lot.

Since for some speakers of English, adnominal too in (46a) is not very natural, it's interesting to consider a German example, where adnominal auch ('too') and hingegen ('however') are usually completely natural. The German judgements in (47) confirm those on the English example in (46) - in particular, adnominal auch is incompatible with the donkey anaphor that has a different antecedent.

(47) Discourse: Jeder, der ein Buch hat, sollte es mitbringen. everyone who a book has should it with bring

a. \#Auch jeder, der ein Kind hat, sollte es/das mitbringen. also everyone who a child has should it with bring

b. Jeder, der ein Kind hat, hingegen, sollte ES/DAS mitbringen. everyone who a child has however should IT with bring

Finally, Elena Anagnostopoulou (p.c.) points out that in modern Greek a strong pronoun is required if and only if the English translation requires focus on the donkey anaphor.

(48) Discourse: Kathe koritsi pu irthe me to aftokinito to parkare sto every girl that came with the car it parked in the garage

garage

a. Kathe koritsi pu irthe me to podhilato to parkare afto stin avli every girl that came with the bike it parked IT in the yard

b. Kathe agori pu irthe me to aftokinito to parkare sto garage every boy that came with the car it parked in the garage

\subsection{Account the Focussability}

The obligatoriness of focus on Donkey Anaphora and the antecedent effect are predicted if Donkey Anaphora are obligatorily hidden definite descriptions as proposed by e.g. Evans (1977) and Cooper (1979). ${ }^{10}$ Consider again example (49) repeated from above.

(49) Discourse: Every owner of a car parked it in the lot

a. Every owner of a BIKE parked IT/\#it in the lot.

The E-type representations for (49) are given in (50). It is clear that the focus is licensed based on these representations.

(50) a. Every owner of a car parked [the car] in the lot. 
b. Every owner of a $[\text { bike }]_{F}$ parked [the bike $]_{F}$ in the lot.

To argue that the focus is obligatory, I adopt one further assumption from Schwarzschild's (1999) semantics of focus-namely, that in many cases certain constituents must obligatorily serve as FD and thereby satisfy in particular the first part of the focus licensing condition (3a) (Givenness). Recall that this condition requires that a discourse antecedent FA must be an element of the focus meaning of FD. Assume, in particular that the whole structure (50b) must satisfy Givenness as FD. Then the only antecedent in question is the structure (50a). However, if the focus on either occurrence of the bike is missing, the Givenness condition isn't satisfied. Therefore the focus on the donkey anaphor is predicted to be obligatory.

If the antecedent is the same in FA and FD, as in (49b), contrastiveness cannot be satisfied as shown by the representations in (51).

a. Every owner of a car parked [the car] in the lot.

b. Every [thief $]_{F}$ of a car parked [the car] in the lot.

Hence, the E-type analysis of donkey anaphora together with the standard theory of focus straightforwardly predicts the above data. ${ }^{11}$

\subsection{Why Ellipsis is Possible}

As (52a) shows, it's possible to elide a VP containing an otherwise obligatorily focussed donkey anaphor. This may seem to case doubt on my claim that the focus on the donkey anaphor is really always obligatory in such examples.

(52) Discourse: Monday night, every girl who was visiting a boy gave him flowers.

a. TUESday night, every girl who was visiting a MAN did.

b. TUESday night, every girl who was visiting a MAN gave HIM CHOColate.

However, it's well known that there are some cases where obligatorily focussed material can be elided. Moreover these cases are structurally alike to (52) except that they involve VP-ellipsis in the place of a donkey anaphor. Schwarz (1999) discusses sentences where VP-ellipsis is possible as in (53a), even though focus is obligatory when the VP isn't elided as in (53b) (see also Kratzer 1991).

(53) a. When I WHIStle you say I shouldn't, but when I SING you DON't.

b. When I WHIStle you say I shouldn't (whistle), but when I SING you DON't say I shouldn't SING/\#sing.

Schwarz (1999) proposes that (53a) should be analyzed as ellipsis of a bound VP pronoun in both conjuncts, as sketched in (54).

(54) [whistle] $\lambda_{v}$ when I $v$ you say I shouldn't $v$, but $[\operatorname{sing}]_{w}$ when I $w$ you don't say I shouldn't $w$. 
The same analysis can be applied to (52), where here it must be ellipsis of a bound NP pronoun. ${ }^{12}$

(55) $\quad[$ boy $] \lambda_{v}$ every girl who was visiting a $v$ gave [the $v$ ] flowers.

a. [man] $\lambda_{w}$ every girl who was visiting a $w$ gave [the $w$ ] flowers.

\section{Appendix: Further Issues Relating to the Antecedent Effect}

The antecedent effect raises a number of issues that I'm still working on. This appendix presents some preliminary results resulting to these matters.

Overlap: Is the antecedent effect observed if the restrictors of the two antecedent quantifiers overlap? It seems that focus is licit in case of overlap ((56b)), unless a sub- or superset relation ((56a) and (57a)) holds.

(56) Discourse: Did every young student call his mother?

a. In fact/No, EVery student called his/\#HIS mother.

b. All I know is that every BLOND student called his/HIS mother.

Discourse: Did every student call his mother?

a. All I know is that every YOUNG student called his/\#HIS mother.

For the FA and FD considered above, this effect isn't predicted. But, consider FA and FD in (58), where A be the restrictor of FA, and B the restrictor of FD:
a. $\mathrm{FA}=$ every $\mathrm{A} \lambda_{1} t_{1}$ called the ${ }_{1}$ A's mother
b. $\mathrm{FD}=$ every $[\mathrm{B}]_{F} \lambda_{2} t_{2}$ called [the ${ }_{2} \mathrm{~B}$ 's $]_{F}$ mother
c. $\mathrm{FD}^{\prime}=$ every $\mathrm{A} \lambda_{2} t_{2}$ called the $\mathrm{A}_{2} \mathrm{~A}^{\prime}$ s mother
d. $\mathrm{FD}^{-}=$every $[\mathrm{B}]_{F} \lambda_{2} t_{2}$ called the ${ }_{2} \mathrm{~B}$ 's mother
e. $\mathrm{FD}^{-\prime}=$ every A $\lambda_{2} t_{2}$ called the ${ }_{2} \mathrm{~B}$ 's mother

If $\llbracket \mathrm{A} \rrbracket \subset \llbracket \mathrm{B} \rrbracket, \llbracket \mathrm{FD}^{-\prime} \rrbracket=\llbracket \mathrm{FA} \rrbracket$. Otherwise, though, (58e) results in a presupposition failure. Hence, the proposal makes the right prediction for (56), but not for (57).

Different extensions: As Orin Percus (p.c.) first pointed out to me, sometimes it's sufficient that the extensions of the two antecedent restrictors differ to license focus on a bound pronoun.

(59) Discourse: Did every flight leave at the time it was scheduled for on Tuesday?

a. All I know is that, on Wednesday, every flight left at the time IT was scheduled for.

This isn't predicted at present. Possibly the issue relates to footnote 5. 
Different quantifiers: Does the quantifier of the antecedent matter for the focussability of a bound pronoun? In the following examples, at least the quantifier seems to be not relevant, as it is predicted.

(60) Discourse: I expected no student to call his mother.

a. But, EVERY student called his/\#HIS mother.

b. But, at least one student called his/\#HIS mother.

Discourse: Did every student call his mother?

a. No, NO student called his/\#HIS mother.

b. All I know is that at least one student called his/\#HIS mother.

However, in more difficult examples where the domains of the quantifiers vary and the quantifiers vary focus is licensed, even if the difference in domains alone wouldn't be sufficient. Consider (62) which was provided by an anonymous reviewer.

(62) Discourse: Almost every contestant used a battery to power his car. a. One Japanese contestant however use a match to power HIS car.

\section{Notes}

I was given little more than three weeks after the conference to write up this paper, which were reduced to three days by other obligations. Regrettably, the great hurry has probably affected the exposition negatively. The only reason to publish the paper in its present is that I hope to get more comments on this work before proceeding with it—my email address is uliealum.mit.edu. I would like to thank those who already helped me with their comments on this version or earlier ones. For useful comments on this version in particular, I'm grateful to Elena Anagnostopoulou, Danny Fox, Graham Katz, Winfried Lechner, Pauline Jacobson, Orin Percus, Wolfgang Sternefeld, Kazuko Yatsushiro, and the audience at SALT 10.

${ }^{1}$ Cf. Rooth's (1992a) Focus Interpretation Principle or Schwarzschild's (1999) Givenness with (63a), Schwarzschild's (1999) Avoid $F$ with (63b).

${ }^{2}$ As pointed out to me by Mats Rooth (p.c) and Marga Reis (p.c.), however allows most easily a hat intonation of the type discussed by Büring (1995) among others. As far as I can see, my argument isn't affected by the difference between hat intonation and a double focus intonation. Therefore, I don't distinguish between the two intonations in the text.

${ }^{3}$ An interesting puzzle is that, when adjoined to a sentence, however requires only one contrast, as shown by (63) in contrast to (15d). I have at present no idea how to relate these two uses of however. For some speakers of English, (15d) is marginally acceptable-I assume that they can leftadjoin however to VP, rather than having to left adjoin it to the subject NP. In German examples with hingegen ('however') this VP-adjunction analysis can be controlled for because of the verb-second property. The English facts in the text can all be reproduced in German.

(63) However, Carl called BERta.

${ }^{4}$ The argument here doesn't refute the claim that differences in indexation can cause focus on pronouns. It only shows that the claim has almost no empirical support: The data considered up to now must all be explained by something else (the proposal in the next section) and are therefore irrelevant to the questions whether indices are used in language and whether they can cause focus.

In addition to other considerations (see von Stechow 1990), there's still an argument for indices remaining: Sauerland $(1998,1999)$ observes that in case FD cannot include the variable binder, focus on a bound pronoun is predicted to be obligatory and presents one (difficult) case that tests this 
prediction. The fact in (64), I think, is a simpler case showing that indices can force focus. However, more work is needed.

(64) a. I said about every boy that Mary called his mother.

b. \#Later, I said about every TEAcher that SUE too called his mother.

c. Later, I said about every TEAcher that SUE however called HIS mother.

${ }^{5}$ Pauline Jacobson (p.c.) provided me with the example (65) which clearly poses a strong challenge to the assumption made in the text. I'm planning to take up this issue in future research.

(65) Every man who loves his mother talked to every man who hates HIS mother.

${ }^{6}$ Elbourne (2000) proposes that the English determiner the is reduced to a pronoun, when it's NP complement is elided. While the idea is attractive, I remain sceptical since the definite determiner der/die/das in German allows ellipsis of its NP-complement, but isn't homophonous to the pronouns er/sie/es. Moreover, definites determiners with NP-ellipsis in German have the distribution of English epithets, and pronouns have the distribution of English pronouns as shown by Wiltschko (1998).

${ }^{7}$ The need for an E-type representation has only been demonstrated in case there's an antecedent with a bound pronoun in the parallel position around. The other alternative to consider is that there's an antecedent like (66) where the parallel position is occupied by some material other than a bound pronoun-if there's no antecedent parallel up to the focussed constituents, destressing of all the other material would not be licensed.

(66) (Only) John brought something Mary likes.

It's quite easy to see that when the index-insensitive focus licensing condition (13b) is adopted, the focus on the bound pronoun is required only on the E-type analysis. If the index-sensitive condition is adopted, the issue is more complicated. Under the assumption, that then only the whole clause is considered as an FD, it follows that then too the focus is only licensed on the E-type analysis of the pronoun.

${ }^{8}$ Kratzer (1998:(23)) observes a similar interaction of focus and binding in the example (67). Her account, however, is very different from mine and doesn't extend to the examples in the text (see also Schlenker 1999).

a. Only I answered a question that you didn't think I could answer. Nobody else answered a question you didn't think I could answer.

b. Only I answered a question that you didn't think i could answer. Nobody else answered a question you didn't think he could answer.

${ }^{9}$ The need to focus seems to be weaker, though, when the two antecedents are both denoting in a similar domain as in (68). Possibly, in this case the following question is accomodated from the discourse: Did every owner of a car park it in the lot? This accomodated question then licenses destressing of the donkey anaphor.

(68) Discourse: Every owner of a Porsche parked it in the lot.

a. Every owner of a MerCEdes too parked it in the lot.

b. Every owner of a MerCEdes however parked IT in the lot.

${ }^{10}$ One might assume the same for unbound pronouns if one were to adopt the index insensitive focus licensing condition in (13b).

${ }^{11}$ In the future, I hope to harness focus on donkey anaphora into a tool to test for what exactly is the content of the donkey anaphor. The idea is illustrated by (69): One part of the sentence differs between the discourse sentence and the target sentence. If this makes it possible to focus the donkey anaphor, this part can be represented in the donkey anaphor. Otherwise, it cannot be. Pauline Jacobson's presentation at SALT 10 contained similar examples with paycheck pronouns.

Discourse: Monday night, every girl who was visiting a boy gave him flowers. 
a. \#TUESday night, every WOMan who was visiting a boy gave HIM CHOColate.

b. Tuesday night, every girl who was inVIting a boy gave him/HIM CHOColate.

\footnotetext{
${ }^{12}$ There's though one remaining difference between VP-ellipsis in (68) and the donkey anaphora cases-namely, the donkey anaphor case requires focus on the reduced definite description, while the reduced VP doesn't allow focus on the remaining modal shouldn't in (68a). At present, I don't have an account of this difference-I take it to indicate that donkey anaphora don't literally involve NP-ellipsis, but a different mechanism of reducing a full DP to a pronoun.
}

\section{References}

Büring, Daniel. 1995. The great scope inversion conspiracy. In Proceedings of SALT 5, ed. by Mandy Simons and Teresa Galloway, 37-53. Cornell, CLC Publications.

Chomsky, Noam. 1993. A minimalist program for linguistic theory. In The View from Building 20, Essays in Linguistics in Honor of Sylvain Bromberger, ed. by Ken Hale and Jay Keyser, 1-52. MIT Press.

Cooper, Robin. 1979. The interpretation of pronouns. In Selections from the Third Groningen Round Table, Syntax and Semantics, Volume 10, ed. by F. Heny and H. Schnelle, 61-92. New York: Academic Press.

Dubinsky, Stanley, and Robert Hamilton. 1998. Epithets as antilogophoric pronouns. Linguistic Inquiry 29.685-693.

Elbourne, Paul. 2000. E-type pronouns as definite articles. Manuscript, MIT.

Evans, Gareth. 1977. Pronouns, quantifiers, and relative clauses, I \& II. The Canadian Journal of Philosophy 7.467-536, 777-797.

Fox, Danny. 1999. Reconstruction, variable binding and the interpretation of chains. Linguistic Inquiry 30.157-196.

Kratzer, Angelika. 1991. The representation of focus. In Semantik: Ein internationales Handuch der zeitgenössischen Forschung (Semantics: An International Handbook of Contemporary Research), ed. by Arnim von Stechow and Dieter Wunderlich, chapter 40, 825-834. Berlin: de Gruyter.

1998. More structural analogies between pronouns and tenses. In Proceedings of SALT 8, 92-110. Ithaca, N.Y., CLC Publications.

Lasnik, Howard. 1976. Remarks on coreference. Linguistic Analysis 2.1-22.

- 1989. On the necessity of binding conditions. In Essays on Anaphora, 149-167. Dordrecht, Netherlands: Kluwer.

Postal, Paul. 1972. "Pronominal Epithets" and similar items. Foundations of Language 9.246-248.

Rooth, Mats. 1992a. A theory of focus interpretation. Natural Language Semantics 1.75116.

- 1992b. Ellipsis redundancy and reduction redundancy. In Proceedings of the Stuttgart Ellipsis Workshop, ed. by Steve Berman and Arild Hestvik. Arbeitspapiere des Sonderforschungsbereichs 340, Bericht Nr. 29, IBM Germany, Heidelberg.

Sauerland, Uli. 1998. The Meaning of Chains. Ph.D. dissertation, Massachusetts Institute of Technology, Cambridge, Mass.

- 1999. Why variables? In Proceedings of NELS 29, ed. by Pius Tamanji, Masako Hirotani, and Nancy Hall, 323-337. Amherst, Mass., GLSA.

Schlenker, Philippe. 1999. Propositional Attitudes and Indexicality. Ph.D. dissertation, Massachusetts Institute of Technology, Cambridge, Mass. 
Schwarz, Bernhard. 1999. Silent verb phrases as bound variables. Manuscript, University of Massachusetts, Amherst.

Schwarzschild, Roger. 1999. Givenness, avoidf and other constraints on the placement of accents. Natural Language Semantics 7.141-177.

Soames, Scott. 1989. Presupposition. In Handbook of Philosophical Logic, vol. IV, ed. by Dov Gabbay and Franz Guenthner, 553-616. Dordrecht, Netherlands: Reidel.

von Stechow, Arnim. 1990. Categorial grammar and linguistic theory. Studies in Language 14.433-478.

Wiltschko, Martina. 1998. On the syntax and semantics of (relative) pronouns and determiners. Journal of Comparative Germanic Linguistics 2.143-181. 